\title{
Congenital Genu Recurvatum
}

\author{
Sharma $D^{1}$, Yadav J², Garg E ${ }^{3}$, Bajaj $\mathrm{H}^{4}$
}

\section{The Case}

A

term baby girl with a weight of $2.8 \mathrm{~kg}$ was born to G2P1L1

mother by normal delivery with an Apgar score of $1 / 3 / 3$. Baby was diagnosed antenatally as case of left sided diaphragmatic hernia with stomach, gut and liver herniated into the chest with mediastinal shift. Chest X-ray showed severe lung hypoplasia with herniated abdominal contents. At birth baby was diagnosed to have genu recurvatum of left knee joint (Fig 1, 2).The other lower limb was normal. There was no other malformation. Baby sucmmed to death with four hours of birth due to severe lung hypoplasia.

\section{Discussion}

Congenital dislocation of the knee (CDK) is a rare circumstance with an incidence rate of about 1 per 100,000 live births. It is characterized by congenital hyperextension of the knee and marked restriction of flexion. This deformity is more common in females ${ }^{1}$. This condition cause knee instability, pain and be associated with shortening of the limbs ${ }^{2,3}$. It can be either a congenital or acquired condition. Three cases have been described: an osseous proximal tibial deformity, soft tissues involving capsule-ligamentous structures and events where a combination of the two exists ${ }^{4,5}$. Early manipulation, combined with splinting and casting is the mainstay of treatment in dislocation. Surgical release of the anterior structures of the knee may be required in patients who present later in life ${ }^{6}$.

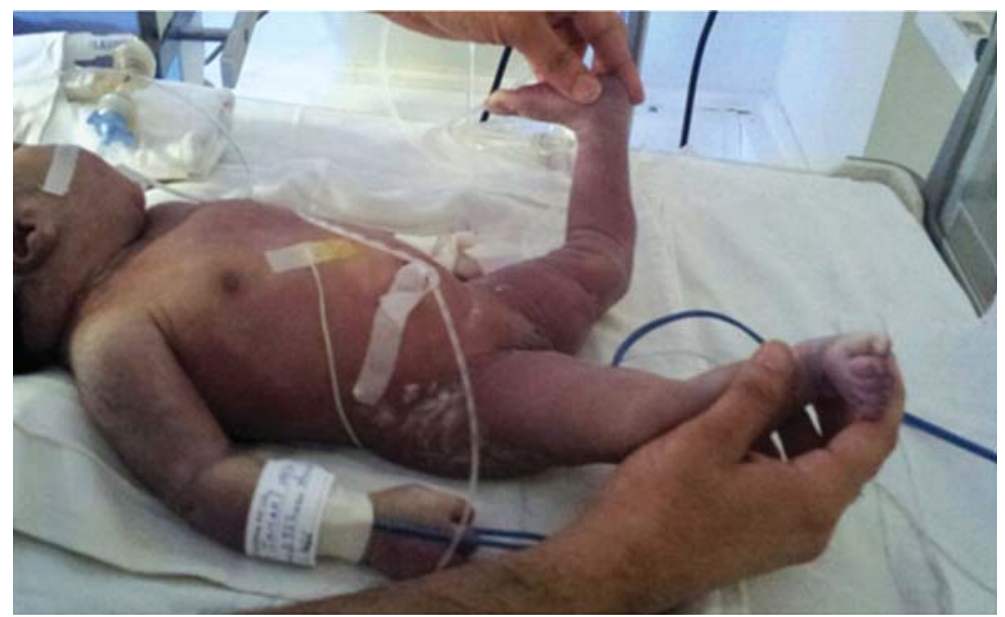

Fig 1: Showing left knee joint genu recurvatum. Note the angulation of knee joint in comparison to right knee joint.
'Dr. Deepak Sharma, MBBS, MD, ${ }^{2}$ Dr. Jaivinder Yadav MBBS, MD, ${ }^{3}$ Dr. Eva Garg, MBBS, DCh, ${ }^{4}$ Dr. Hanish Bajaj, MBBS, DCh. All from the Department of Paediatrics, Pt. B.D.S PGIMS Rohtak, Haryana, India.

Address for correspondence:

Dr. Deepak Sharma

E-mail: dr.deepak.rohtak@gmail.com

\section{How to cite}

Sharma D, Yadav J, Garg E, Bajaj H. Congenital Genu Recurvatum. J Nepal Paediatr Soc 2014;34(2):168169.

doi: http://dx.doi.org/10.3126/jnps.v34i2.9890

This work is licensed under a Creative Commons Attribution 3.0 License.

\section{(c) (i)}

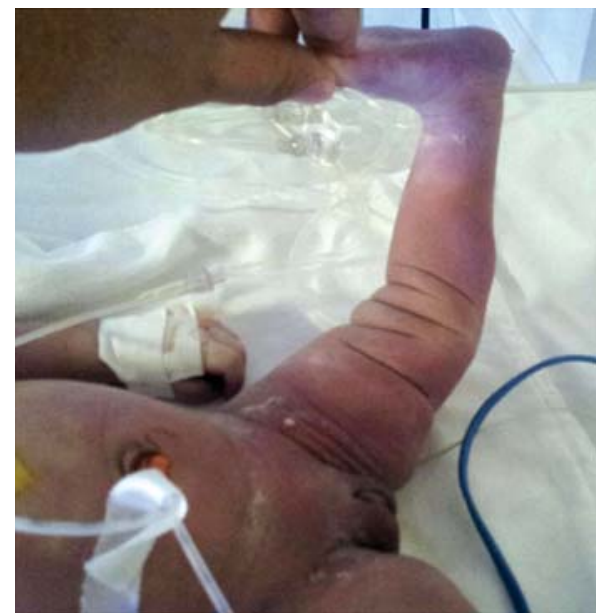

Fig 2: Showing left knee joint genu recurvatum. Note the angulation of knee joint in comparison to right knee joint and fold of skin on the knee joint. 


\section{References}

1. Fernandez PF and Silva JR. Congenital dislocation of the knee. Int Orthop 1990; 14:17-19.

2. J. Perry, J. P. O’Brien, A. R. Hodgson. Triple Tenodesis of the Knee. A Soft-Tissue Operation for the Correction of Paralytic Genu Recurvatum. J Bone Joint Surg 1976;58:978-85.

3. A. M. Pappas, P. Anas and H. M. Toczylowski Jr., "Asymmetrical Arrest of the Proximal Tibial Physis and Genu Recurvatum Deformity," J Bone Joint Surg 1984;66:575-81
4. F. Lecuire, J. L. Lerat, G. Bousquet, H. Dejour and A. Trillat, "The Treatment of Genu Recurvatum (Author's Transl)," Revue de Chirurgie Orthopedique et Repa-ratrice de L Appareil Moteur 1980;66:95-103

5. T. M. Van Raaij, M. J. de Waal. Anterior Opening Wedge Osteotomy of the Proximal Tibia for Anterior Knee Pain in Idiopathic Hyperextension Knees . Intl Orthop 2006;30:248-52.

6. Curtis BH, Fischer RL. Congenital hyperextension and anterior subluxation of the knee: Surgical treatment \& long term observation. J Bone Joint Surg (Am) 1969; 51:255-69. 